\title{
Composição morfológica da forragem consumida por bovinos de corte durante o rebaixamento do capim-marandu submetido a estratégias de pastejo rotativo
}

\author{
Júlio Kuhn da Trindade ${ }^{(1)}$, Sila Carneiro da Silva(2), Salim Jacaúna de Souza Júnior(2), \\ Alessandra Aparecida Giacomini(2), Cauê Varesqui Zeferino(2), Vítor DelAlamo Guarda(2) e Paulo César de Faccio Carvalho(1) \\ (1)Universidade Federal do Rio Grande do Sul, Fac. de Agronomia, Av. Bento Gonçalves, № 7.712, CEP 91501-970 Porto Alegre, RS. \\ E-mail: julio.trindade@ufrgs.br, paulocfc@ufrgs.br (2)Escola Superior de Agricultura Luiz de Queiroz, Av. Pádua Dias, no 11, CEP 13418-900 \\ Piracicaba, SP.E-mail: scdsilva@esalq.usp.br, sjsouza@esalq.usp.br, giacomin@esalq.usp.br, cvzeferino@esalq.usp.br, \\ vguarda@esalq.usp.br
}

\begin{abstract}
Resumo - O objetivo deste trabalho foi avaliar o efeito de estratégias de pastejo rotativo sobre a composição morfológica da forragem consumida por bovinos de corte em pastos de Brachiaria brizantha cv. Marandu. Os pastejos foram realizados sempre que o dossel atingia 95 ou $100 \%$ de intercepção luminosa (IL) até as alturas pós-pastejo de 10 e $15 \mathrm{~cm}$. Foi avaliada a composição morfológica das extrusas coletadas de animais fistulados no esôfago em três etapas ao longo do rebaixamento dos pastos. À medida que o rebaixamento progrediu, a proporção de lâminas foliares na extrusa diminuiu e a de colmos e de material morto aumentou. Pastejos iniciados com $100 \%$ de IL ou realizados até a altura pós-pastejo de $10 \mathrm{~cm}$ resultaram em menor proporção de lâminas foliares e maior de colmos e de material morto. O tratamento 95/15 foi consistente entre os tratamentos que apresentaram as maiores proporções de lâminas foliares e menores de colmos e de material e, mesmo no final do rebaixamento, apresentou, ainda, mais de $50 \%$ de proporção de lâminas foliares na extrusa. Os resultados obtidos indicam que, durante o rebaixamento do dossel, pastejos mais freqüentes e menos severos proporcionam aos animais a obtenção de dietas com elevada proporção de lâminas foliares, o que deve aumentar o valor nutritivo da forragem consumida.
\end{abstract}

Termos para indexação: Brachiaria brizantha, composição da dieta, fístula esofagiana, extrusa, componentes morfológicos, rebaixamento do pasto.

\section{Morphological composition of the herbage consumed by beef cattle during the grazing down process of marandu palisadegrass subjected to rotational strategies}

\begin{abstract}
The objective of this work was to evaluate the effect of rotational grazing strategies on the morphological composition of the herbage consumed by beef cattle in Brachiaria brizantha cv. Marandu swards. Grazings were carried out when swards achieved 95 and $100 \%$ of light interception (LI) until postgrazing heights of 10 and $15 \mathrm{~cm}$. Morphological composition of the herbage consumed was determined from extrusa samples harvested from oesophageal-fistulated animals in three occasions, during the grazing down process. As sward height decreased from the pre-grazing condition, the proportion of leaf laminae in the extrusa decreased, and that of stems and dead material increased. Grazing at $100 \% \mathrm{LI}$ or at $10 \mathrm{~cm}$ postgrazing height resulted in lower proportion of leaf laminae and higher proportion of stems and dead material than grazing at $95 \%$ LI or $15 \mathrm{~cm}$ postgrazing height. The treatment 95/15 ranked consistently among those with the highest proportions of leaf laminae, lowest proportions of stems and dead material; and, at the end of the grazing session, it still had 50\% of leaf laminae in the extrusa. In general, the results indicate that more frequent and less severe grazings favour animal to feed on forage with a high proportion of leaf laminae, which increases diet nutritive value.
\end{abstract}

Index terms: Brachiaria brizantha, diet composition, oesophageal fistulae, extrusa, morphological components, grazing down process.

\section{Introdução}

O pasto é responsável por grande parte da produção pecuária no Brasil e no mundo. A presença do animal é, sem dúvida, um dos principais fatores que singularizam o ambiente pastoril, e a compreensão dos seus efeitos dentro do ecossistema se faz necessária, para que se possa explorá-lo ao máximo, de maneira racional e sustentável (Sbrissia \& Silva, 2001). Ao contrário de sistemas de confinamento, onde os animais são colocados a ingerir um alimento em quantidades e concentrações de nutrientes balanceadas, em pastagens os herbívoros 
deparam-se com o alimento distribuído de forma heterogênea no espaço e no tempo. Segundo Carvalho et al. (1999), a complexidade dessa distribuição impõe ao animal em pastejo o desafio de obter uma dieta de alta qualidade, em quantidade suficiente para atender suas necessidades nutricionais.

O processo de pastejo e, conseqüentemente, o desempenho e a produtividade animal são afetados por componentes ligados à arquitetura e à proporção dos componentes morfológicos e botânicos, presentes no pasto, que definem a estrutura vertical e horizontal do dossel (Laca \& Lemaire, 2000). O manejo do pastejo pode ser estabelecido pelo controle da frequiência e intensidade da desfolhação (Carnevalli et al., 2006; Barbosa et al., 2007; Pedreira et al., 2007), combinação essa que afeta a estrutura do dossel. Zeferino (2006) trabalhou com a combinação de duas freqüências (pastejo iniciado quando o dossel interceptasse $95 \mathrm{ou}$ $100 \%$ de luz incidente) e duas intensidades de pastejo (representadas por 10 e $15 \mathrm{~cm}$ de altura pós-pastejo), em pastos de Brachiaria brizantha cv. Marandu, e demonstrou que períodos de descanso longos $-100 \%$ de interceptação luminosa (IL) - resultaram em maior alongamento e acúmulo de colmos e senescência que períodos de descanso mais curtos, representados pelos tratamentos $95 \%$ de IL. Barbosa et al. (2007) encontraram, para pastos de Panicum maximum cv. Tanzânia submetidos às maiores frequiências $(90 \%$ e $95 \%$ de IL) e maior intensidade de pastejo ( $25 \mathrm{~cm}$ de altura pós-pastejo), maior porcentual de lâminas foliares na massa de forragem pré-pastejo. Em contrapartida, pastos submetidos à menor freqüência $(100 \%$ de IL) $\mathrm{e}$ menor intensidade de pastejo $(50 \mathrm{~cm}$ de altura póspastejo) apresentaram maiores proporções de colmos e de material morto.

A estrutura do dossel é extremamente importante, pois determina a acessibilidade e a facilidade de colheita de componentes, normalmente selecionados pelos animais em pastejo, e afeta, em última análise, a quantidade ingerida de nutrientes (Stobbs, 1973). Segundo Hodgson (1990), a dieta do animal em pastejo geralmente contém alta proporção de lâminas foliares e baixa proporção de colmos e de material morto.

A presença de lâminas foliares na estrutura do dossel, relativamente a outros componentes morfológicos, corresponde a uma condição importante para satisfazer as necessidades nutricionais dos animais (Stobbs, 1973; Genro, 1999; Gontijo Neto et al., 2006). A componente lâmina foliar é identificada como a de maior valor nutricional. No entanto, em pastejo rotativo, alterações na estrutura do dossel, à medida que o pasto é rebaixado, podem causar modificações na composição da forragem consumida. Chacon \& Stobbs (1976) concluíram que a componente morfológica folha é uma das que mais afetam o consumo dos animais em pastejo. Além disso, Stobbs (1973) apontou que existem grandes diferenças em quantidade e qualidade da folha e de valor nutritivo da forragem desde o topo até a base do dossel, e que a acessibilidade às folhas seria dificultada durante os estágios finais do processo de rebaixamento dos pastos.

Assim, em pastejo rotativo, a estratégia de manejo adotada tem efeito sobre as possíveis escolhas que os animais realizam, e essas são determinadas pelas modificações na estrutura do dossel que ocorrem durante o rebaixamento dos pastos.

O objetivo deste trabalho foi avaliar o efeito de estratégias de pastejo rotativo sobre a composição morfológica da forragem consumida por bovinos de corte em pastos de Brachiaria brizantha cv. Marandu.

\section{Material e Métodos}

O experimento foi conduzido pelo Grupo de Estudos com Plantas Forrageiras (GEPF), na Unidade Experimental de Plantas Forrageiras (UEPF), em área do Departamento de Zootecnia, da Escola Superior de Agricultura Luiz de Queiroz, pertencente à Universidade de São Paulo, no Município de Piracicaba, SP, a $22^{\circ} 42^{\prime} S$, $47^{\circ} 37^{\prime} \mathrm{W}$ e $550 \mathrm{~m}$ de altitude (Ometto, 1981).

O período experimental compreendeu avaliações entre novembro de 2005 e abril de 2006, e foi dividido em duas épocas do ano: primavera, com avaliações realizadas durante novembro e dezembro de 2005; e verão, com avaliações realizadas de janeiro a abril de 2006.

Os tratamentos experimentais corresponderam à combinação entre duas intensidades e dois intervalos entre pastejos: um pastejo intenso, que representa um elevado nível de eficiência de utilização da forragem produzida, caracterizado pela altura pós-pastejo de $10 \mathrm{~cm}$, e um pastejo mais leniente, caracterizado pela altura pós-pastejo de $15 \mathrm{~cm}$. Essas intensidades foram combinadas com dois intervalos entre pastejos, um correspondente ao tempo necessário para que o dossel forrageiro atingisse índice de área foliar que permitisse a interceptação de $95 \%$ da luz incidente, e outro quando valores próximos de $100 \%$ de interceptação luminosa fossem atingidos. Odelineamento experimental utilizado foi o inteiramente casualizado, com três repetições, num total de 12 unidades experimentais (piquetes de $1.200 \mathrm{~m}^{2}$ ). 
Durante a rebrotação, o monitoramento da altura dos pastos e da interceptação de luz era feito a cada incremento de $5 \mathrm{~cm}$, a partir da altura pós-pastejo (Zeferino, 2006). A altura dos pastos foi monitorada por meio de régua, com a qual foram realizadas 20 leituras em pontos aleatórios de cada unidade experimental. A altura de cada ponto correspondeu à altura média do dossel em torno da régua (plano de visão), e a média dos 20 pontos correspondeu à altura média da unidade experimental (piquete). A interceptação de luz pelos pastos foi monitorada com um aparelho analisador de dossel LI-COR, modelo LAI 2000. Foram utilizadas 10 estações de leitura (amostragem) por piquete, compostas de 5 leituras no nível do solo e uma leitura correspondente, acima do nível do dossel, em cada estação, no total de 50 leituras no nível do solo e 10 acima do dossel por piquete.

Para o rebaixamento dos pastos, durante a condução do experimento, foram utilizadas novilhas e vacas da raça Nelore com peso médio inicial de 350 e $540 \mathrm{~kg}$, respectivamente. Os pastejos foram realizados com o método de pastejo em grupo ("mob grazing”) (Mislevy et al., 1981; Gildersleeve et al., 1987), e o lote de animais foi dimensionado para que o rebaixamento ocorresse entre $7 \mathrm{~h}$ (momento de entrada do lote de rebaixamento) e 19h (momento de saída do lote de rebaixamento).

Para o monitoramento do rebaixamento, medidas de altura do dossel foram realizadas em intervalos de tempo que variaram de 30 a 90 min de permanência dos animais nos piquetes. O método usado foi o da régua ("sward stick") Barthram (1985), tendo-se realizado 100 leituras por piquete para compor o valor médio de altura dos pastos.

Duas novilhas fistuladas no esôfago, previamente habituadas ao procedimento experimental, foram utilizadas para as coletas da forragem consumida (extrusa). O peso médio dessas novilhas era de $515 \mathrm{~kg}$ no período experimental. Com o intuito de induzi-las a pastejar no momento das avaliações, durante o rebaixamento, e evitar a contaminação da extrusa colhida por material de ruminação, optou-se por deixá-las em jejum, em local próximo aos piquetes que estavam sendo avaliados, por cerca de seis horas, antes do início até o final das avaliações.

Após a colocação dos bornais coletores de extrusa, as duas novilhas fistuladas no esôfago eram levadas para os piquetes, onde continuavam sendo utilizadas em turnos de avaliação de 15 min cada. Ao final de cada turno, as duas novilhas eram retiradas dos piquetes e colocadas em bretes móveis, alocados próximos aos piquetes, e as extrusas eram colhidas e enviadas imediatamente para o laboratório. Nessa ocasião, as extrusas foram acondicionadas e congeladas em freezer, para posterior determinação da composição morfológica.

Os turnos de avaliação foram realizados em três etapas, durante o rebaixamento: etapa inicial, quando a altura do estrato pastejável (altura pré e pós-pastejo) diminuía entre 0 ( $7 \mathrm{~h}$ ) e $25 \%$; etapa intermediária, quando a altura do estrato pastejável diminuía entre 25 e $75 \%$; e etapa final, quando a altura do estrato pastejável diminuía entre 75 e 100\% (final do período de ocupação dos pastos - aproximadamente às $19 \mathrm{~h}$ ). Para a realização das avaliações feitas com as novilhas fistuladas, eram retirados os animais do lote de rebaixamento das parcelas, os quais eram rotineiramente conduzidos a uma área de reserva próxima até o final das avaliações.

Após o término do período experimental, foram realizadas análises da composição morfológica das extrusas que estavam armazenadas em freezer. Cada amostra foi descongelada e envolta por um pano, antes de ser lavada em água corrente por 1 a 2 min com o objetivo de se retirar o excesso de saliva e facilitar a posterior visualização dos fragmentos morfológicos e botânicos (adaptado de Heady \& Torell, 1959). Encerrada a lavagem, a amostra era homogeneizada e dela retirada alíquota (entre 10 a $20 \mathrm{~g}$ ) para ser espalhada sobre uma bandeja de vidro. No fundo da bandeja, foi reproduzida uma grade quadriculada com 493 quadrículos de $1 \mathrm{~cm}^{2}$ cada. Antes do início do período de análises foram aleatorizados todos os vértices contidos na grade de quadrículos e sorteados os 100 primeiros para a marcação. Sob os vértices marcados, foram realizados os procedimentos para análise da amostra.

Com a alíquota da amostra sobre a bandeja quadriculada, colocou-se um filme de água (aproximadamente $50 \mathrm{~mL}$ ), e procedeu-se à agitação, no plano horizontal da bandeja, para espalhar os fragmentos. Sobre os 100 vértices previamente demarcados, foram coletados todos os fragmentos presentes, com auxílio de pinça cirúrgica, os quais eram, em seguida, acondicionados em bandejas de plástico identificadas para cada fragmento coletado. Os fragmentos de capim-marandu coletados, identificados com o auxílio de lupa óptica (10x) quando necessário, foram classificados como lâminas foliares, colmos (colmos+ bainhas) e material morto.

Os dados obtidos de composição da extrusa geraram uma estimativa da presença em proporção (número de vértices para cada componente no total de 100 vértices amostrados -\%) 
de cada um dos componentes morfológicos em cada amostra analisada, e foram submetidos à análise de variância com o PROC MIXED (modelos mistos) do SAS. Para a escolha da matriz de variância e covariância utilizou-se o critério de informaçãoAkaike (Wolfinger, 1993). Dessa maneira, foram detectados os efeitos das causas de variação de interceptação luminosa pré-pastejo, altura pós-pastejo, etapa do rebaixamento e época do ano, além das interações entre elas, que foram considerados como fixos (Littel et al., 2000). As médias dos tratamentos foram estimadas utilizando-se o LSMEANS, e a comparação entre elas foi realizada por meio da probabilidade da diferença (PDIFF) pelo teste t de Student, a $10 \%$ de probabilidade. Por se tratar de variáveis controladas, os valores de interceptação luminosa do dossel e altura pré e pós-pastejo não foram submetidos à análise de variância.

\section{Resultados e Discussão}

Os valores nominais de interceptação luminosa pelo dossel, registrados na condição pré-pastejo, atingiram a meta de $95 \%$ para os tratamentos de $95 \%$ de IL, mas corresponderam ao valor médio de $97,9 \%$ para os tratamentos de $100 \%$ de IL (Tabela 1). Esse fato ocorreu porque o aparelho utilizado nas avaliações não registra o valor de $100 \%$ de IL, mesmo em condições de completa escuridão (Carnevalli et al., 2006). Na condição pré-pastejo,

Tabela 1. Médias da interceptação luminosa (\%) pré-pastejo de pastos de capim-marandu submetidos a estratégias de pastejo rotativo.

\begin{tabular}{cccc}
\hline Altura pós-pastejo $(\mathrm{cm})$ & \multicolumn{3}{c}{ Interceptação luminosa (\%) } \\
\cline { 2 - 3 } & 95 & & 100 \\
\hline \multicolumn{3}{c}{95,0} & Primavera \\
15 & 95,9 & 97,9 \\
10 & \multicolumn{3}{c}{ Verão } \\
15 & 95,0 & & 97,9 \\
\hline
\end{tabular}

o valor médio de altura, nas duas épocas do ano, foi $24,1 \mathrm{~cm}$ para os tratamentos de $95 \%$ de IL e $32,4 \mathrm{~cm}$ para os tratamentos de $100 \%$ de IL (Tabela 2). Para plantas de clima tropical, resultados de experimentação recente têm revelado relação assintótica entre a altura do dossel e a interceptação da radiação luminosa incidente, e um valor relativamente estável em que $95 \%$ de IL é atingido para cada planta forrageira (Silva, 2004). Isso indica que a altura, na condição pré-pastejo, pode ser utilizada como um indicador prático de campo para o manejo do pastejo (Silva \& Corsi, 2003; Mello \& Pedreira, 2004; Difante, 2005; Carnevalli et al., 2006; Zeferino, 2006; Barbosa et al., 2007; Pedreira et al., 2007).

A meta de altura pós-pastejo para os tratamentos de resíduo $15 \mathrm{~cm}$ ficou muito próxima da altura preestabelecida (Tabela 2). Os tratamentos de altura póspastejo $10 \mathrm{~cm}$ apresentaram valores acima do planejado, especialmente o tratamento 100/10. Resposta semelhante foi reportada por Carnevalli et al. (2006) e Barbosa et al. (2007) ao trabalhar com Panicum maximum cultivares Mombaça e Tanzânia, respectivamente, com variações de até $60 \%$ acima das metas de altura póspastejo registradas. Segundo Trindade (2007), os padrões de desfolhação alteram a estrutura do dossel e determinam, próximo ao final do período de ocupação, um dossel composto por muitos perfilhos tipo vareta, caracterizados pela ausência quase total de lâminas foliares, restando apenas colmos, estruturas de maior resistência à colheita e que dificultam o rebaixamento do pasto.

No início do pastejo, a proporção de lâminas foliares na extrusa foi elevada comparativamente à proporção de colmos e de material morto (Tabela 3). No entanto, com o transcorrer do rebaixamento, ocorreram modificações na estrutura do dossel, que não permitiram ao animal manter a colheita de lâminas foliares de forma análoga ao que ocorria na fase inicial do processo, mesmo com elevada seletividade dos animais.

Tabela 2. Médias da altura $(\mathrm{cm})$ pré-pastejo e pós-pastejo em pastos de capim-marandu submetidos a estratégias de pastejo $\operatorname{rotativo}^{(1)}$.

\begin{tabular}{|c|c|c|c|c|}
\hline \multirow[t]{2}{*}{ Altura pós-pastejo (cm) } & \multicolumn{2}{|c|}{ Pré-pastejo } & \multicolumn{2}{|c|}{ Pós-pastejo } \\
\hline & $95 \%^{(2)}$ & $100 \%$ & $95 \%$ & $100 \%$ \\
\hline & \multicolumn{4}{|c|}{ Primavera } \\
\hline 10 & $26,6(2,51)$ & $32,3(2,21)$ & $10,1(2,39)$ & $12,0(1,75)$ \\
\hline 15 & $27,6(1,86)$ & $38,1(2,06)$ & $14,4(0,33)$ & $15,3(1,56)$ \\
\hline \multicolumn{5}{|c|}{ Verão } \\
\hline 10 & $20,2(0,61)$ & $29,1(5,16)$ & $7,7(0,82)$ & $12,0(1,15)$ \\
\hline 15 & $21,8(3,30)$ & $30,0(2,57)$ & $12,7(1,54)$ & $13,5(2,73)$ \\
\hline
\end{tabular}

(1)Valores entre parênteses correspondem ao desvio-padrão da média. (2)Interceptação luminosa de 95 e $100 \%$. 
De maneira geral, a proporção de lâminas foliares diminuiu (Tabela 4) e a de material morto aumentou ao longo do processo de rebaixamento (Tabela 5), o que também ocorreu com a proporção de colmos $(7,4 \pm 0,50$

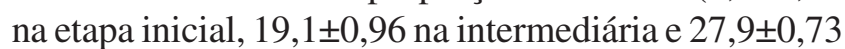
na final). Orr et al. (2004) demonstraram, durante o rebaixamento do pasto, que a massa de lâminas foliares foi positivamente correlacionada à massa do bocado, $\mathrm{e}$ Prache \& Peyraud (1997) identificaram a massa de lâminas foliares como um determinante importante do consumo. Chacon \& Stobbs (1976) reportaram valores de proporção de folhas na extrusa superiores a $90 \%$ e mostraram que o teor de nitrogênio e a digestibilidade da forragem consumida diminuíram com o rebaixamento. Esse fato sugere a importância de se encontrar o melhor momento de retirada dos animais dos piquetes com base em parâmetros estruturais do dossel (por exemplo, altura), como forma de manter um consumo elevado de lâminas foliares e uma dieta de alto valor nutritivo.

Os animais colheram forragem com maior proporção de lâminas foliares tanto nos tratamentos de $95 \%$ de IL quanto nos tratamentos de altura póspastejo $15 \mathrm{~cm}$ durante todas as etapas do rebaixamento, exceto para os tratamentos de IL na etapa inicial do pastejo (Tabela 4). Os tratamentos

Tabela 3. Níveis de significância das causas de variação (interceptação luminosa, altura pós-pastejo, etapa do rebaixamento e época do ano), sobre as variáveis proporção de lâminas foliares, colmos e material morto na forragem consumida pelos animais em pastos de capim-marandu submetidos a estratégias de pastejo rotativo ${ }^{(1)}$.

\begin{tabular}{lccc}
\hline Causa de variação & \multicolumn{3}{c}{ Variáveis } \\
\cline { 2 - 4 } & PFE & PCE & PME \\
\hline IL & 0,0075 & 0,0558 & 0,0532 \\
APP & 0,0005 & 0,0017 & 0,0016 \\
APP*IL & ns & ns & 0,0543 \\
ER & $<0,0001$ & $<0,0001$ & $<0,0001$ \\
ER*IL & 0,0611 & ns & 0,0896 \\
ER*APP & 0,0169 & ns & 0,0029 \\
ER*IL*APP & 0,0462 & ns & 0,0295 \\
EP & 0,0803 & 0,0936 & 0,0491 \\
EP*IL & 0,0017 & 0,0503 & 0,0015 \\
EP*APP & ns & ns & ns \\
EP*APP*IL & 0,0141 & 0,0116 & ns \\
EP*ER & 0,0710 & ns & 0,0828 \\
EP*ER*APP & ns & 0,0714 & ns \\
EP*ER*IL & 0,0234 & 0,0782 & 0,0016 \\
IL*APP*ER*EP & 0,0358 & 0,0905 & ns \\
\hline
\end{tabular}

(1)IL: interceptação luminosa; APP: altura pós-pastejo; ER: etapa do rebaixamento; EP: época do ano; PFE: proporção de lâminas foliares na extrusa; PCE: proporção de colmos na extrusa; PME: proporção de material morto na extrusa. de $100 \%$ de IL e os tratamentos com altura póspastejo $10 \mathrm{~cm}$ resultaram nas maiores proporções de colmo e de material morto das extrusas (Tabelas 6 e 5, respectivamente). Pastos submetidos a períodos de descanso mais longos, como os de $100 \%$ de IL, possuíam presença significativa de colmo e de material morto no estrato pastejável (Trindade, 2007), conseqüência do acúmulo considerável desses componentes durante, particularmente, o final do período de rebrotação, depois que $95 \%$ de IL são atingidos (Carnevalli et al., 2006; Zeferino, 2006; Barbosa et al., 2007; Pedreira et al., 2007). Portanto, o consumo desse tipo de componente morfológico ocorreu em maior quantidade, em relação àquele nos pastos submetidos a períodos de descanso mais curtos (95\% de IL). Esse fato é particularmente importante se a altura pós-pastejo almejada for baixa e o objetivo

Tabela 4. Médias da proporção de lâminas foliares (\%) na extrusa de bovinos de corte durante o rebaixamento de pastos de capim-marandu submetidos a estratégias de pastejo rotativo $^{(1)}$.

\begin{tabular}{|c|c|c|c|}
\hline \multirow{2}{*}{$\begin{array}{c}\text { Altura } \\
\text { pós-pastejo } \\
\text { (cm) } \\
\end{array}$} & \multicolumn{2}{|c|}{ Interceptação luminosa (\%) } & \multirow[t]{2}{*}{ Média } \\
\hline & 95 & 100 & \\
\hline & \multicolumn{3}{|c|}{ Etapa inicial } \\
\hline 10 & $88,2(1,49) \mathrm{AB}^{\prime}$ & $86,1(1,52) \mathrm{B}^{\prime}$ & $87,1(1,07) \mathrm{Ab}$ \\
\hline 15 & $91,2(1,49) \mathrm{A}^{\prime}$ & $90,7(1,49) \mathrm{A}^{\prime}$ & $91,0(1,05) \mathrm{Aa}$ \\
\hline Média & $89,7(1,05) \mathrm{Aa}$ & $88,4(1,07) \mathrm{Aa}$ & $89,0(0,75) \mathrm{A}$ \\
\hline & \multicolumn{3}{|c|}{ Etapa intermediária } \\
\hline 10 & $69,5(2,80) \mathrm{A}^{\prime}$ & $60,5(2,81) \mathrm{B}^{\prime}$ & $65,0(1,98) \mathrm{Bb}$ \\
\hline 15 & $75,3(2,81) \mathrm{A}^{\prime}$ & $70,2(2,81) \mathrm{A}^{\prime}$ & $72,8(1,98) \mathrm{Ba}$ \\
\hline Média & $72,4(1,98) \mathrm{Ba}$ & $65,4(1,98) \mathrm{Bb}$ & $68,9(1,40) \mathrm{B}$ \\
\hline & \multicolumn{3}{|c|}{ Etapa final } \\
\hline 10 & $33,9(2,92) \mathrm{B}^{\prime}$ & $33,2(3,02) \mathrm{B}^{\prime}$ & $33,5(2,10) \mathrm{Cb}$ \\
\hline 15 & $55,5(2,92) \mathrm{A}^{\prime}$ & $39,9(2,92) \mathrm{B}^{\prime}$ & $47,7(2,05) \mathrm{Ca}$ \\
\hline Média & $44,7(2,07) \mathrm{Ca}$ & $36,5(2,10) \mathrm{Cb}$ & $40,6(1,47) \mathrm{C}$ \\
\hline & \multicolumn{3}{|c|}{ Média } \\
\hline 10 & $63,9(1,54)$ & $59,9(1,56)$ & $61,9(1,10) \mathrm{B}$ \\
\hline 15 & $74,0(1,54)$ & $65,0(1,54)$ & $70,4(1,10) \mathrm{A}$ \\
\hline Média & $68,9(1,09) \mathrm{a}$ & \multicolumn{2}{|l|}{$63,5(1,10) \mathrm{b}$} \\
\hline \multicolumn{4}{|c|}{$\begin{array}{l}\text { (1) Valores entre parênteses correspondem ao erro-padrão da média; } \\
\text { médias de tratamentos (IL/altura pós-pastejo), dentro de cada etapa do } \\
\text { rebaixamento e na média geral, seguidas de letras iguais maiúsculas } \\
\text { acrescidas de ('), não diferem entre si ( }>0,10 \text { ); médias de IL entre as } \\
\text { etapas do rebaixamento, seguidas por letras iguais, maiúsculas na coluna } \\
\text { e minúsculas na linha, não diferem entre si, pelo teste t a } 10 \% \text { de } \\
\text { probabilidade; médias da mesma altura pós-pastejo entre as etapas do } \\
\text { rebaixamento, seguidas de letras iguais maiúsculas, não diferem entre si, } \\
\text { pelo teste t a } 10 \% \text { de probabilidade; médias de altura pós-pastejo, dentro } \\
\text { de cada etapa do rebaixamento, seguidas de letras iguais minúsculas, ou } \\
\text { seguidas de letras iguais maiúsculas na média geral, não diferem entre si, } \\
\text { pelo teste t a } 10 \% \text { de probabilidade; médias de etapas do rebaixamento } \\
\text { seguidas de letras iguais maiúsculas não diferem entre si, pelo teste t } \\
\text { a } 10 \% \text { de probabilidade. }\end{array}$} \\
\hline
\end{tabular}


Tabela 5. Médias da proporção de material morto (\%) na extrusa de bovinos de corte durante o rebaixamento dos pastos de capim-marandu submetidos a estratégias de pastejo rotativo ${ }^{(1)}$.

\begin{tabular}{|c|c|c|c|}
\hline \multirow{2}{*}{$\begin{array}{c}\text { Altura } \\
\text { pós-pastejo } \\
\text { (cm) }\end{array}$} & \multicolumn{2}{|c|}{ Interceptação luminosa (\%) } & \multirow[t]{2}{*}{ Média } \\
\hline & 95 & 100 & \\
\hline \multicolumn{4}{|c|}{ Etapa inicial } \\
\hline 10 & $1,4(0,35) \mathrm{AB}^{\prime}$ & $1,9(0,35) \mathrm{A}^{\prime}$ & $1,7(0,25) \mathrm{Ca}$ \\
\hline 15 & $1,2(0,35) \mathrm{AB}^{\prime}$ & $0,7(0,35) \mathrm{B}^{\prime}$ & $1,0(0,25) \mathrm{Cb}$ \\
\hline Média & $1,3(0,25) \mathrm{Ca}$ & $1,3(0,25) \mathrm{Ca}$ & $1,3(0,17) \mathrm{C}$ \\
\hline \multicolumn{4}{|c|}{ Etapa intermediária } \\
\hline 10 & $10,1(1,35) \mathrm{AB}^{\prime}$ & $12,0(1,35) \mathrm{A}^{\prime}$ & $11,0(0,96) \mathrm{Ba}$ \\
\hline 15 & $7,0(1,35) \mathrm{B}^{\prime}$ & $9,7(1,35) \mathrm{AB}^{\prime}$ & $8,4(0,96) \mathrm{Bb}$ \\
\hline Média & $8,6(0,96) \mathrm{Ba}$ & $10,8(0,96) \mathrm{Ba}$ & $9,7(0,68) \mathrm{B}$ \\
\hline \multicolumn{4}{|c|}{ Etapa final } \\
\hline 10 & $35,7(2,46) \mathrm{A}^{\prime}$ & $33,4(2,50) \mathrm{AB}^{\prime}$ & $34,6(1,75) \mathrm{Aa}$ \\
\hline 15 & $18,4(2,46) \mathrm{C}^{\prime}$ & $29,6(2,46) \mathrm{B}^{\prime}$ & $24,0(1,74) \mathrm{Ab}$ \\
\hline Média & $27,1(1,74) \mathrm{Ab}$ & $31,5(1,75) \mathrm{Aa}$ & $29,3(1,24) \mathrm{A}$ \\
\hline \multicolumn{4}{|c|}{ Média } \\
\hline 10 & $15,7(0,99) \mathrm{A}^{\prime}$ & $15,8(1,00) \mathrm{A}^{\prime}$ & $15,8(0,70) \mathrm{a}$ \\
\hline 15 & $8,9(0,99) \mathrm{B}^{\prime}$ & $13,4(0,99) \mathrm{A}^{\prime}$ & $11,1(0,70) \mathrm{b}$ \\
\hline Média & $12,3(0,70) \mathrm{b}$ & $14,6(0,70) \mathrm{a}$ & \\
\hline \multicolumn{4}{|c|}{$\begin{array}{l}\text { (1) Valores entre parênteses correspondem ao erro-padrão da média; } \\
\text { médias de tratamentos (IL/altura pós pastejo), dentro de cada etapa do } \\
\text { rebaixamento e na média geral, seguidas por letras maiúsculas iguais, } \\
\text { acrescida de ('), não diferem entre si pelo teste t, a } 10 \% \text { de probabilidade; } \\
\text { médias de IL, entre as etapas do rebaixamento, seguidas por letras } \\
\text { iguais, maiúsculas na coluna e minúsculas na linha, não diferem entre si } \\
\text { pelo teste t, a } 10 \% \text { de probabilidade; médias de altura pós-pastejo do } \\
\text { rebaixamento seguidas por letras iguais, maiúsculas entre as etapas e } \\
\text { minúsculas em cada etapa e na média geral, não diferem entre si pelo } \\
\text { teste t, a } 10 \% \text { de probabilidade; médias de etapa do rebaixamento seguidas } \\
\text { de letras maiúsculas iguais não diferem entre si pelo teste t, a } 10 \% \text { de } \\
\text { probabilidade. }\end{array}$} \\
\hline
\end{tabular}

Tabela 6. Médias da proporção de colmos (\%) na extrusa de bovinos de corte durante o rebaixamento dos pastos de capimmarandu submetidos a estratégias de pastejo rotativo ${ }^{(1)}$.

\begin{tabular}{|c|c|c|c|}
\hline \multirow{2}{*}{$\begin{array}{c}\text { Altura } \\
\text { pós-pastejo } \\
(\mathrm{cm})\end{array}$} & \multicolumn{2}{|c|}{ Interceptação luminosa (\%) } & \multirow[t]{2}{*}{ Média } \\
\hline & 95 & 100 & \\
\hline \multicolumn{4}{|c|}{ Primavera } \\
\hline 10 & $15,8(1,19) \mathrm{B}^{\prime}$ & $22,8(1,19) \mathrm{A}^{\prime}$ & \\
\hline 15 & $15,0(1,19) \mathrm{B}^{\prime}$ & $15,9(1,19) \mathrm{B}^{\prime}$ & \\
\hline Média & $15,4(0,84) \mathrm{Bb}$ & $19,3(0,84) \mathrm{Aa}$ & $17,3(0,59) \mathrm{B}$ \\
\hline \multicolumn{4}{|c|}{ Verão } \\
\hline 10 & $22,4(1,27) \mathrm{A}^{\prime}$ & $19,8(1,31) \mathrm{AB}^{\prime}$ & \\
\hline 15 & $15,6(1,27) \mathrm{C}^{\prime}$ & $18,2(1,27) \mathrm{BC}^{\prime}$ & \\
\hline Média & $19,0(0,90) \mathrm{Aa}$ & $19,0(0,91) \mathrm{Aa}$ & $19,0(0,64) \mathrm{A}$ \\
\hline \multicolumn{4}{|c|}{ Média } \\
\hline 10 & $19,1(0,87)$ & $21,3(0,88)$ & $20,2(0,62) \mathrm{A}$ \\
\hline 15 & $15,3(0,87)$ & $17,0(0,87)$ & $16,2(0,62) \mathrm{B}$ \\
\hline Média & $17,2(0,62) \mathrm{b}$ & $19,2(0,62) \mathrm{a}$ & \\
\hline
\end{tabular}

(1)Valores entre parênteses correspondem ao erro-padrão da média; médias de tratamentos (IL/ altura pós-pastejo), dentro de cada época do ano, seguidas de letras iguais maiúsculas, acrescidas de ('), não diferem entre si, pelo teste $\mathrm{t}$ a $10 \%$ de probabilidade; médias de IL, entre as épocas do ano, seguidas por letras iguais, maiúsculas na coluna e minúsculas na linha, não diferem entre si, pelo teste t a $10 \%$ de probabilidade; médias de época e médias de altura pós-pastejo, seguidas por letras maiúsculas iguais na coluna não diferem entre si, pelo teste t a $10 \%$ de probabilidade. for condicionar os animais a obterem sua dieta num horizonte composto por grande proporção de colmos e de material morto. Isso sugere que se deve definir adequadamente os momentos de entrada e saída dos animais dos pastos, início e término do período de ocupação, uma vez que a estrutura do dossel formada, durante a rebrotação, afeta diretamente a composição da forragem consumida pelos animais.

O tratamento $100 / 10$ foi o que resultou nas menores proporções de lâminas foliares na extrusa dos animais, particularmente durante a segunda metade do processo de rebaixamento dos pastos (Tabela 4). Além disso, foi o tratamento que esteve classificado entre aqueles que apresentaram as maiores proporções de colmos e de material morto (Tabelas 6 e 5, respectivamente). Por outro lado, o tratamento 95/15 foi o que resultou na maior proporção de lâminas foliares durante todas as fases do rebaixamento, mesmo durante a última fase do rebaixamento, condição em que ainda apresentava mais de $50 \%$ da extrusa composta por lâminas foliares, no momento da saída dos animais dos piquetes. Esse mesmo tratamento esteve entre os tratamentos que apresentaram as menores proporções de colmo e de material morto na forragem consumida.

A massa do bocado é um dos determinantes principais do consumo de forragem em situação de pastejo (Laca \& Ortega, 1995). Segundo Trindade (2007), em trabalho sobre comportamento ingestivo de animais em pastejo com o capim-marandu, a massa do bocado foi menor quando os pastejos foram realizados com $95 \%$ de IL e altura pós-pastejo de $15 \mathrm{~cm}$, o que sugere que o desempenho animal poderia ser aquém do ótimo. No entanto, no presente trabalho, o tratamento 95/15 foi o que apresentou a maior proporção de lâminas foliares na forragem consumida em relação aos demais tratamentos, fato esse que poderia compensar, parcial ou totalmente, a menor ingestão de forragem por bocado. A maior proporção de lâminas foliares poderá conferir ao alimento consumido pelos animais maior degradabilidade e menor tempo de retenção no rúmen (Poppi et al., 1987), o que possibilitará maior consumo no longo prazo.

Com relação às épocas do ano, o verão foi a época em que a proporção de material morto na forragem consumida foi menor (Tabela 7) e a de lâminas foliares maior $(64,7 \pm 1,06 \%$ na primavera e 
Tabela 7. Médias da proporção de material morto (\%) na extrusa de bovinos de corte durante o rebaixamento dos pastos de capim-marandu manejados até atingirem 95 e $100 \%$ de interceptação de luz pelo dossel, durante a rebrotação em duas épocas do ano ${ }^{(1)}$.

\begin{tabular}{lccc}
\hline \multirow{2}{*}{ Época } & \multicolumn{2}{c}{ Interceptação luminosa $(\%)$} & \multirow{2}{*}{ Média } \\
\cline { 2 - 3 } & 95 & 100 & \\
\hline Primavera & $11,1(0,97) \mathrm{Ab}$ & $18,0(0,97) \mathrm{Aa}$ & $14,6(0,68) \mathrm{A}$ \\
Verão & $13,5(0,99) \mathrm{Aa}$ & $11,1(0,99) \mathrm{Ba}$ & $12,3(0,70) \mathrm{B}$ \\
\hline
\end{tabular}

${ }^{(1)}$ Valores entre parênteses correspondem ao erro-padrão da média; médias seguidas por letras iguais, maiúsculas nas colunas e minúsculas nas linhas, não diferem entre si pelo teste t, a $10 \%$ de probabilidade.

$67,7 \pm 1,10 \%$ no verão). Esse fato pode estar relacionado à maior atividade microbiana no solo e à decomposição de matéria orgânica durante os meses mais quentes e chuvosos do ano, o que levaria à menor proporção de material morto nos pastos durante o verão (Molan, 2004; Carnevalli et al., 2006) e causaria redução desse componente na extrusa dos animais. No entanto, durante o verão, foram observados valores maiores de proporção de colmos na extrusa em relação à primavera (Tabela 6). $\mathrm{O}$ verão é a época do ano em que ocorre o maior acúmulo de colmos (Zeferino, 2006), fato esse que deve ter contribuído para as maiores proporções desse componente na extrusa dos animais durante os pastejos de verão relativamente àqueles de primavera.

\section{Conclusões}

1. A composição morfológica da extrusa de animais fistulados no esôfago sofre alterações significativas em conseqüência das modificações da estrutura do dossel ao longo do rebaixamento, afetando a ingestão de nutrientes e o desempenho de animais em pastejo.

2. O manejo do pastejo permite criar ambientes pastoris que favorecem o consumo de componentes morfológicos de alto valor nutritivo.

3. O manejo mais adequado é aquele com pastejos realizados quando $95 \%$ da luz incidente são interceptados pelo dossel à altura pós-pastejo de $15 \mathrm{~cm}$.

\section{Agradecimentos}

À Fapesp, pela concessão de bolsa; ao Prof. Domício do Nascimento Júnior, pelas sugestões e comentários durante a elaboração do trabalho.

\section{Referências}

BARBOSA, R.A.; NASCIMENTO JÚNIOR, D.; EUCLIDES, V.P.B.; SILVA, S.C. da; ZIMMER, A.H.; TORRES JÚNIOR, R.A.A. Capim-tanzânia submetido a combinações entre intensidade e freqüência de pastejo. Pesquisa Agropecuária Brasileira, v.42, p.329-340, 2007.

BARTHRAM, G.T. Experimental techniques: the HFRO sward stick. In: The Hill Farming Research Organization Biennial Report 1984/1985. Penicuik: HFRO, 1985. p.29-30.

CARNEVALLI, R.A.; SILVA, S.C. da; BUENO, A.A.O.; UEBELE, M.C.; BUENO, F.O.; SILVA, G.N.; MORAES, J.P. Herbage production and grazing losses in Panicum maximum cv. Mombaça under four grazing managements. Tropical Grasslands, v.40, p.165176, 2006

CARVALHO, P.C.F.; PRACHE, S.; DAMASCENO, J.C. O processo de pastejo: desafios da procura e apreensão da forragem pelo herbívoro. In: REUNIÃO ANUAL DA SOCIEDADE BRASILEIRA DE ZOOTECNIA, 36., 1999, Porto Alegre. Anais. Porto Alegre: SBZ, 1999. v.2. p.253-268.

CHACON, E.; STOBBS, T.H. Influence of progressive defoliation of a grass sward on the eating behavior of cattle. Australian Journal of Agricultural Research, v.27, p.709-727, 1976.

DIFANTE, G.S. Desempenho de novilhos, comportamento ingestivo e consumo voluntário em pastagem de Panicum maximum Jacq. cv. Tanzânia. 2005. 74p. Tese (Doutorado) Universidade Federal de Viçosa, Viçosa.

GENRO, T.C.M. Estimativas de consumo em pastejo e suas relações com os parâmetros da pastagem em gramíneas tropicais. 1999. 130p. Tese (Doutorado) - Universidade Federal do Rio Grande do Sul, Porto Alegre.

GILDERSLEEVE, R.R.; OCUMPAUGH, W.R.; QUESENBERRY, K.H.; MOORE, J.E. Mobgrazing morphologically different Aeschynomene species. Tropical Grasslands, v.21, p.123-132, 1987.

GONTIJO NETO, M.M.; EUCLIDES, V.P.B.; NASCIMENTO JÚNIOR, D.; MIRANDA, L.F.; FONSECA, D.M.; OLIVEIRA, M.P. Consumo e tempo de pastejo por novilhos Nelore em pastagem de capim-tanzânia sob diferentes ofertas de forragem. Revista Brasileira de Zootecnia, v.35, p.60-66, 2006.

HEADY, F.H.; TORELL, D.T. Forage preference exhibited by sheep with esophageal fistulas. Journal of Range Management, v.12, p.28-33, 1959.

HODGSON, J. Grazing management: science into pratice. New York: J. Wiley: Longman Scientific and Technical, 1990. 203p.

LACA, E.A.; LEMAIRE, G. Measuring sward structure. In: T'MANNETJE, L.; JONES, R.M. (Ed.). Field and laboratory methods for grassland and animal production research. New York: Cabi, 2000. p.103-122.

LACA, E.A.; ORTEGA, I.M. Integrating foraging mechanisms across spatial and temporal scales. In: INTERNATIONAL RANGELANDS CONGRESS, 5., 1995, Salt Lake City. Proceedings. Salt Lake City: Society for Range Management, 1995. p.129-132.

LITTEL, R.C.; PENDERGAST, J.; NATARAJAN, R. Modelling covariance structure in the analysis of repeated measures data. Statistics in Medicine, v.19, p.1793-1819, 2000. 
MELLO, A.C.L.; PEDREIRA, C.G.S. Respostas mofológicas do capim-tanzânia (Panicum maximum Jacq. cv. Tanzânia-1) irrigado à intensidade de desfolha sob lotação rotacionada. Revista Brasileira de Zootecnia, v.33, p.282-289, 2004.

MISLEVY, P.; MOTT, G.O.; MARTIN, F.G. Screening perennial forages by mob-grazing technique. In: INTERNATIONAL GRASSLAND CONGRESS, 14., 1981, Lexington. Proceedings. Boulder: Westview Press, 1981. p.516-519.

MOLAN, L.K. Estrutura do dossel, interceptação luminosa e acúmulo de forragem em pastos de capim-marandu submetidos a alturas de pastejo por meio de lotação contínua. 2004. 159p. Dissertação (Mestrado) - Escola Superior de Agricultura Luiz de Queiroz, Piracicaba.

OMETTO, J.C. Bioclimatologia vegetal. São Paulo: Agronômica Ceres, 1981. 425p.

ORR, R.J.; RUTTER, S.M.; YARROW, N.H.; CHAMPION, R.A.; ROOK, A.J. Changes in ingestive behaviour of yearling dairy heifers due to changes in sward state during grazing down of rotationally stocked ryegrass or white clover pastures. Applied Animal Behaviour Science, v.87, p.205-222, 2004.

PEDREIRA, B.C.; PEDREIRA, C.G.S.; SILVA, S.C. da. Estrutura do dossel e acúmulo de forragem de Brachiaria brizantha cultivar Xaraés em resposta a estratégias de pastejo. Pesquisa Agropecuária Brasileira, v.42, p.281-287, 2007.

POPPI, D.P.; HUGHES, T.P.; L'HUILLIER, P.J. Intake of pasture by grazing ruminants. In: NICOL, A.M. (Ed.). Livestock feeding on pasture. Hamilton: New Zealand Society of Animal Production, 1987. p.55-64. (Occasional publication, 10).

PRACHE, S.; PEYRAUD, J. Préhensiblité de l'herbe pâturée chez lês bovins et lês ovins. Productions Animales, v.10, p.377-390, 1997.
SAS INSTITUTE (Cary, Estados Unidos). SAS/STAT: user's guide, Version 8.0. Cary: 2000. 5v.

SBRISSIA, A.F.; SILVA, S.C. da. O ecossistema de pastagens e a produção animal. In: MATTOS, W.R.S. (Ed.). A produção animal na visão dos brasileiros. Piracicaba: SBZ, 2001. p.731-753.

SILVA, S.C. da. Understanding the dynamics of herbage accumulation in tropical grass species: the basis for planning efficient grazing management practices. In: PIZARRO, E.; CARVALHO, P.C.F.; SILVA, S.C. da; DITTRICH, J.R. (Ed.). INTERNATIONAL SYMPOSIUM ON GRASSLAND ECOPHYSIOLOGY AND GRAZING ECOLOGY, 2., 2004, Curitiba. Proceedings. Curitiba: UFPR, 2004. 1CD-ROM.

SILVA, S.C. da; CORSI, M. Manejo do pastejo. In: SIMPÓSIO SOBRE MANEJO DA PASTAGEM, 20., 2003, Piracicaba. Anais. Piracicaba: Fealq, 2003. p.155-186.

STOBBS, T.H. The effect of plant structure on the intake of tropical pastures. II. Differences in sward structure, nutritive value, and bite size of animals grazing Setaria anceps and Chloris gayana at various stages of growth. Australian Journal of Agricultural Research, v.24, p.821-829, 1973.

TRINDADE, J.K. Modificações na estrutura do pasto e no comportamento ingestivo de bovinos durante o rebaixamento do capim-marandu submetido a estratégias de pastejo rotacionado. 2007. 162p. Dissertação (Mestrado) - Escola Superior de Agricultura Luiz de Queiroz, Piracicaba.

WOLFINGER, R. Covariance structure selection in general mixed models. Communication in Statistics, v.22, p.1079-1106, 1993.

ZEFERINO, C.V. Morfogênese e dinâmica do acúmulo de forragem em pastos de capim-marandu [Brachiaria brizantha (Hochst. ex A. Rich) cv. Marandu] submetidos a regimes de lotação intermitente por bovinos de corte. 2006. 193p. Dissertação (Mestrado) - Escola Superior de Agricultura Luiz de Queiroz, Piracicaba.

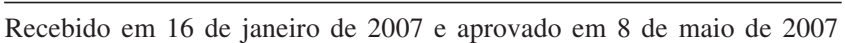

